Student-Led, Asynchronous Collaborative Online Discussions

\title{
An Exploratory Examination of Student-Led, Asynchronous Collaborative Online Discussions in Fostering Higher-Order Cognitive Skills and Ethical Leadership Learning
}

\author{
Graziella Pagliarulo McCarron \\ Larisa Olesova \\ Brianna Calkins \\ George Mason University, USA
}

\begin{abstract}
Previous studies have contextualized student-led, asynchronous online discussions as collaborative learning experiences that positively impact students' learning and foster higher order cognitive skills. From a leadership education perspective, student-led discussions have come to the fore as a helpful resource for deepening learning because of their focus on collaboration and shared leadership. While literature on student-led online discussions, leadership learning, and cognitive skill is plentiful, there is no single study that explores all these elements together or fully points to how practicing meaning-making in online, asynchronous leadership courses can inform larger cognitive processes. Thus, the purpose of this conceptual content analysis-based study was to examine 35 undergraduate students' collaborative discussion board posts at the beginning, middle, and end of an online, asynchronous Ethics and Leadership class to assess not only if and to what extent students expressed cognitive skills, in general, but also if and to what extent they understood ethical leadership via these types of discussions. Further, from an exploratory lens, this study examined if there was a relationship between expression of higher order cognitive skills and more complex ethical leadership understanding. Results indicate that, while students achieved higher order cognitive skills and more holistic ethical leadership understanding overall, robustness of student engagement could be situational in nature and expressions of cognitive skills and ethical leadership understanding tapered as the course progressed. Additional findings and implications are discussed.
\end{abstract}

Keywords: Asynchronous, student-led discussions, cognitive skill, online leadership studies

McCarron, G. P., Olesova, L., Calkins, B. (2021). An exploratory examination of student-led, asynchronous collaborative online discussions in fostering higher-order cognitive skills and ethical leadership learning. Online Learning, 25(4), 198-219. DOI: 10.24059/olj.v25i4.2895 
Reviews of college and university enrollments from 2003-04 to 2015-16 illustrate that the percentage of undergraduates registered in online courses increased from $15.6 \%$ to $43.1 \%$ (de Brey et. al, 2019), and this figure does not even account for the upswell attributed to learning pivots due to the 2020-21 COVID-19 pandemic. While online delivery formats vary (e.g., synchronous, asynchronous, hybrid), critiques of asynchronous pedagogies are abundant and often center on diminished learning and community engagement and decreases in relationshipbuilding and collaborative learning (Moallem, 2015; Peterson et al., 2018; Roseth et al., 2011). Yet, asynchronous modalities are often deemed the most flexible given that students have few to no required virtual class meetings, can engage the course in ways congruent with their own schedules (Hrastinski, 2018; Lim, 2017), and can more easily balance education and work/life obligations (Harasim, 2000). One specific element of asynchronous online learning that has gained attention for its capacity to offer flexibility, enhance learning, and mitigate class engagement concerns is the collaborative discussion board.

Aloni and Harrinton (2018) and Perrotta (2020) noted that using discussion boards in asynchronous courses is important for promoting deeper understanding of course material and subject matter proficiency. Further, studies have contextualized asynchronous discussion boards as collaborative learning experiences that positively impact the development of students' higher order cognitive skills, particularly when students take an active leadership role and facilitate the discussion (Hew \& Cheung, 2011; Waters, 2012) (i.e., student-led discussions). From a disciplinary perspective, these student-led online discussions have come to the fore in leadership education as helpful resources for deepening learning (e.g., McRay et al., 2016; Smith, 2015) and developing leadership understanding (Bleich, 2020). Leadership, described as "a relational and ethical process of people together attempting to accomplish positive change" (Komives et al., 2013, p. 33), is scaffolded by connection and conversation. Given the salience of collaboration and relational processes in leadership education (Higher Education Research Institute [HERI], 1996; Komives et al., 2016) as well as the designation of discussion as a "signature pedagogy" in leadership learning (Jenkins, 2016), student-led online discussion boards are essential to curriculum and overall student learning and development, and they warrant further exploration.

This exploration is of particular importance about the intersection between student-led discussions and cognitive skill, which, according to Yang et al. (2011), speaks directly to individuals' capacity to move from conceptual understanding to more complex application of theory to lived experiences. While literature on student-led online discussions, leadership learning, and cognitive skill is plentiful, no single study has explored these elements together. Understanding these components is important to creating engaging online learning environments for students that leverage real-world experience aimed at bolstering leadership development. Moreover, this holistic exploration may shed light on how fostering collaborative knowledge construction in student-led discussions can inform and transfer to cognitive processes in leadership and other disciplines. This exploration is even more important in the context of the undergraduate experience because most studies focused on the purpose and outcomes of studentled online discussions center graduate students (see Baran \& Correia, 2009; Chen et al., 2019; de Oliveira \& Olesova, 2013). Thus, the purpose of this conceptual content analysis-based study was to examine 35 undergraduate students' collaborative discussion board posts at the beginning, middle, and end of an online, asynchronous Ethics and Leadership class to assess not only if and to what extent students expressed cognitive skills, in general, but also if and to what extent they 
understood ethical leadership via these types of discussions. Further, from an exploratory lens, this study examined if there was a relationship between expression of higher order cognitive skills and more complex ethical leadership understanding.

This exploratory research was guided by the following research questions:

(a) If and to what extent do students express cognitive skills via weekly student-led discussions over the course of the term?

(b) If and to what extent do students express ethical leadership understanding via weekly student-led discussions over the course of the term?

(c) What, if any, is the relationship between expression of cognitive skill and ethical leadership understanding?

(d) What, if any, is the relationship between cognitive skill, ethical leadership

understanding, and select student demographics (academic program, GPA, and prior leadership coursework)?

We believe this study is significant because it will make a new contribution to the online learning and leadership education literature regarding the place of collaborative, student-led, asynchronous online discussions, and it will offer implications for enhanced undergraduate learning. Further, not only will it add to the work on online pedagogy and leadership education, but it may also begin to unpack the associations between student demographics and successful engagement in online, collaborative learning. For example, while Hsu et al. (2003) found that the level of students' participation in online collaborative learning could be predicted by grade point average (GPA), Williams and Lahman (2011) found no link between students' critical thinking in online discourse and GPA. Lastly, this study is significant because exploring the parallels between cognitive skills and leadership learning may illuminate new ways via which we can use collaborative pedagogy to foster deeper thinking across disciplines, support students toward holistic understanding, and connect instructional designers and leadership faculty more fully.

\section{Literature Review}

\section{Collaborative, Student-Led Online Discussions and Cognitive Skill}

Digital collaboration - defined as occurrences in which "individuals are responsible for their actions, including learning and respecting the abilities and contribution of their peers" (Laal \& Ghodsi, 2012, p. 486) - is a valuable instructional approach that can help students make deeper meaning of content. Student-student interaction in asynchronous, online discussions and, specifically, in student-led discussions, can foster collaborative knowledge construction because active facilitation requires a stronger focus on building upon others' contributions and offering new ideas (De Wever et al., 2010; Jeanneau \& O'Riordan, 2020). Contrary to instructor-led discussion, student-led discussion is based on lateral relationships (peer-to-peer), not on a hierarchical relationship (e.g., expert-novice) (Hew, 2005), and when students facilitate discussions, they usually engage in leadership by taking on meaningful facilitation roles (Baran \& Correia, 2009). As facilitators, students ask questions, clarify, or justify their position or reexamine their ideas, provide comments to their classmates about whether they agree or disagree, and summarize discussions. All these student facilitation strategies reflect an explicit relationship to the higher levels of cognitive learning (Schindler \& Burkholder, 2014).

Cognitive skill is one component of cognitive learning and refers to complex thinking aimed at synthesis, application, and creation of new meaning (Schindler \& Burkholder, 2014). Several models examine students' cognitive skill in asynchronous online discussions. For example, Gunawardena et al.'s (1997) five-phase model explores socially constructed knowledge 
in online discussions through the perspective of phases from sharing/comparing of information to application of newly constructed meaning. The model centers negotiation of meaning via students' thinking changes because of their engagement in cognitive activities in online discussions. Similar to Gunawardena et al.'s framework, Garrison et al. (2001) proposed the Practical Inquiry model, which is based on Dewey's (1938) work prioritizing reflection processes connected to searching for/exchanging ideas, comparing, contrasting, and explaining solutions, and testing solutions in online discussions.

While Gunawardena et al.'s (1997) five-phase model and Garrison et al.'s (2001) Practical Inquiry framework have been used extensively in the field of instructional design, both present with validity issues (Rourke et al., 2001). In response, Yang et al. (2011) developed, validated, and tested a content analysis model for assessing cognitive learning in online discussions that assesses two dimensions of cognitive learning-i.e., knowledge and cognitive skill (or processes for exhibiting knowledge). As proposed by Yang et al. (and defined in this current study), cognitive skill speaks to the intellectual activities that process information and is comprised of a five-factor continuum codifying students' capacity for (a) sharing and describing information, (b) explaining, comparing, interpreting, and clarifying, (c) analyzing and concluding, (d) applying, and (e) creating. Yang et al.'s model is informed by the revised Bloom's Taxonomy (Anderson et al., 2001), which centers the cognitive processes of remembering, understanding, applying, analyzing, evaluating, and creating, and it is applicable to general online discussions as well as discussions specifically related to problem-solving activities.

\section{Collaborative, Student-Led Online Discussions and Leadership Learning}

Rost and Barker (2000) underscored that "leadership education is aimed at producing citizens for a democratic society" (p. 1) by emphasizing "collaboration, wholeness, consensus, client-orientation, civic virtues..." (p. 5) and laboring toward "global connections, diversity, pluralism, critical dialogue, and multidisciplinary perspectives" (p. 5). The roots of modern-day student leadership education and development programs can be found in the 1970s as leadership studies (as a field) flowered and rudimentary leadership frameworks crystalized (Komives et al., 2006). The years since have more fully centered the importance of college-based leadership learning both inside and outside of the classroom (e.g., Dugan \& Humbles, 2018; Guthrie et al., 2016; Owen, 2015). Given that belonging, inclusion, ethical pluralism, relationship, and dialogue are intrinsic to leadership education, online discussions serve as a living laboratory for learning.

In their assessment of ways to engage students in introductory leadership courses, Smith (2015) underscored the value of asynchronous online discussion boards in connecting students to leadership theory and promoting "authenticity and meaningful exchange" (p. 232). Similarly, Jenkins (2016), in their examination of salient leadership pedagogies, found that student-led discussion boards were among the most utilized strategies. Leadership education centers human interaction and collaboration (Rost \& Barker, 2020), and, as such, student-led discussion boards and collaborative learning pedagogies are not only helpful to learning, but also essential to lifelong leadership development. This connection becomes even more important as we negotiate turbulent societal times (e.g., pandemic, changing needs of students), the natural growth of online learning communities (Friedman, 2018), and the increasing salience of online leadership education (Jenkins, 2016). Yet, while scholars have produced excellent research examining the development of strong leadership pedagogies for digital spaces (Guthrie \& Meriwether, 2018; Jenkins, 2016; McCarron et al., 2020; Purcell, 2017), we have yet to dig deeply into the relationship between leadership learning, collaborative learning via online, student-led 
discussion boards, and the linkages between students' meaning making of leadership concepts and cognitive skill development. This examination is essential if our aims are to strengthen online collaborative learning not only in leadership education, but also writ large.

\section{Conceptual Framework}

Given that the aim of this study was to identify representations of general cognitive skill as well as representations of holistic ethical leadership understanding, the work was guided by two conceptual frameworks. Regarding cognitive skill, Yang et al.'s (2011) content analysis model for assessing students' cognitive learning in asynchronous online discussions served as guide. The model assessed two dimensions of cognitive learning-i.e., knowledge and cognitive skill. Cognitive skill, the focus of this study, is comprised of a five-factor continuum codifying students' capacity for (a) sharing and describing information, (b) explaining, comparing, interpreting, clarifying, (c) analyzing and concluding, (d) applying, and (e) creating. Yang et al.'s model moves from foundational understanding to more complex (i.e., higher order) expressions of thinking. To keep our analysis as pointed as possible, we pared down the framework to factors $\mathrm{a}, \mathrm{b}$, and d. The complete rationale for this choice is noted in Data Analysis below.

Regarding leadership, we opted to focus on ethical leadership meaning making given the aims of the course. As such, the Relational Leadership Model (RLM), presented by Komives et al. (2013), provided a basis for teasing out students' understanding of ethical leadership. The RLM includes five core components that inform how leadership processes might be framed. First, the RLM notes that the leadership process is just that, a process, grounded in iteration, group synergy, and "continuous meaning-making” (Dugan, 2017, p. 238; Komives et al., 2013). Additionally, the RLM underscores that leadership processes must be inclusive, empowering, ethical, and purposeful, and involve "knowing" (i.e., being knowledgeable), "being" (i.e., being aware of self and others), and "doing" (i.e., acting and applying learning) (Komives et al., 2013). This idea of knowing, being, and doing is particularly salient in that it also intersects with the notion of discourse and language (see Gee, 2015). Language - as expressed through discussion board posts in our study - could serve as a tool for students to inform, act, and be, thus, growing in their learning and meaning making complexity.

Both Yang et al.'s (2011) framework and the RLM speak to holistic thinking and share parallels in how meaning-making can move from simple to complex-e.g., from knowing to acting in the ethical component of the RLM and from describing to applying in the cognitive skill model. However, it is imperative to underscore that, while the cognitive skills model may move from lower to higher order, the RLM does not move on such a continuum but rather speaks to holism based on knowing, being, and doing. Yet, given the synergy between frameworks, we engage them in an exploratory fashion toward assessing students' online discussions.

\section{Research Design}

\section{Methodology}

The aim of this examination was to identify representations of cognitive skill as well as holistic ethical leadership understanding in undergraduate student-led online discussions. As such, a content analysis of students' weekly discussion posts was conducted based on its aptness in previous studies for categorizing narrative to draw conclusions (e.g., Rose et al., 2015) as well as assessing individuals' thinking skills (e.g., Johansson, 2020; Ulum, 2016). Our content analysis was conceptual in nature in that codes and concepts were scaffolded, informed, and directed by existing frameworks (see Hsieh \& Shannon, 2005). 


\section{Setting and Context}

The weekly discussion board posts assessed in this study were part of a required assignment for a fully online, asynchronous Ethics and Leadership course. This course is offered in both Fall and Spring semesters as part of major and minor requirements in a Leadership and Organizational Development degree track; it enrolls major/minor students as well as students seeking an elective. Critical learning outcomes for the course include students' capacity to articulate and apply key ethical decision-making principles, and supporting assignments range from reading and journaling to experiential site visits and leader interviews. In this study, we focus on one of the collaborative learning requirements for the course - the Ethical Leadership in the News (ELIN) assignment - which requires teams of three-four students (assigned by the instructor with one student designated as "team coach" to shepherd the process) to create a slidebased presentation for a pre-determined week linking class theory to current events.

As part of the ELIN team assignment, presenting students collaborate to summarize and compare weekly readings, describe the connection between those readings and the current event, and craft four class discussion questions. Questions must map to the cognitive processes noted in the revised Bloom's Taxonomy (see Anderson et al., 2001): remembering, understanding, applying, analyzing, evaluating, and creating. Students are provided with sample question stems that speak to each of these six processes (see Appendix A for sample questions). Once students develop the presentation and questions, the course instructor provides students with feedback and an additional discussion question typically focused on application, analysis, or evaluation. Once students incorporate instructor feedback, they post the presentation to the course discussion board. Over the course of the subsequent week, all enrolled students respond to the ELIN team's discussion questions and are required, by set days, to comment meaningfully on the responses of four or more classmates, respond to any questions posed of them, and, if presenting, offer a closing synthesis statement at week's end. In all, students post a minimum of five times. The weekly discussions run from Week 4 through Week 13 of the 16-week Ethics and Leadership class. The instructor is heavily involved in the weekly discussions and participates actively both in encouraging students as well as challenging them to dig deep in their responses.

\section{Participants}

Our Institutional Review Board-approved study was supported by secondary data, via which we examined pre-existing participant responses to "investigate new or additional research questions" (Heaton, 2008, p. 35); therefore, we did not recruit participants. The study sample included 35 of 41 students enrolled in the Ethics and Leadership course. Given that analysis focused on students who had posted responses to the discussion questions for all the weekly ELIN discussions, six students who did not post consistently were excluded from the study. While students represented a range of ages, academic programs, gender and racial identities, and enrollment statuses, not all demographic information was available for the participants. Accessible participants' demographics that are germane to this study can be found in Table 1 . 
Table 1

Participant Student Profiles $(N=35)$

\begin{tabular}{|c|c|c|c|}
\hline Pseudonym & Academic Program & GPA to Grade Conversion & Prior Leadership Coursework \\
\hline Anca & Non- Leadership & B or Higher & Yes \\
\hline Ann & Non- Leadership & Below B & Yes \\
\hline Arla & Non- Leadership & B or Higher & Yes \\
\hline Alma & Leadership & Below B & Yes \\
\hline Amy & Leadership & Below B & Yes \\
\hline Anabelle & Non- Leadership & B or Higher & Yes \\
\hline Bette & Non- Leadership & B or Higher & Yes \\
\hline Barb & Non- Leadership & B or Higher & Yes \\
\hline Christie & Non- Leadership & B or Higher & Yes \\
\hline Cate & Non- Leadership & B or Higher & Yes \\
\hline Cali & Non- Leadership & B or Higher & Yes \\
\hline Connie & Non- Leadership & B or Higher & Yes \\
\hline Carl & Non- Leadership & B or Higher & Yes \\
\hline Dell & Non- Leadership & B or Higher & Yes \\
\hline Donnie & Non- Leadership & Below B & Yes \\
\hline Enid & Non- Leadership & Below B & No \\
\hline Edith & Non- Leadership & B or Higher & Yes \\
\hline Holly & Non- Leadership & B or Higher & Yes \\
\hline Jeri & Non- Leadership & B or Higher & No \\
\hline Krisia & Leadership & B or Higher & No \\
\hline Marsha & Non- Leadership & B or Higher & No \\
\hline Mary & Non- Leadership & B or Higher & Yes \\
\hline Marshall & Leadership & B or Higher & No \\
\hline Norma & Leadership & B or Higher & No \\
\hline $\mathrm{Nia}$ & Non- Leadership & B or Higher & Yes \\
\hline Olga & Non- Leadership & B or Higher & Yes \\
\hline Evanie & Non- Leadership & B or Higher & No \\
\hline Ruth & Non- Leadership & Below B & Yes \\
\hline Ronni & Non- Leadership & B or Higher & No \\
\hline Raina & Non- Leadership & B or Higher & Yes \\
\hline Susan & Non- Leadership & B or Higher & No \\
\hline Sol & Non- Leadership & B or Higher & Yes \\
\hline Stella & Non- Leadership & B or Higher & No \\
\hline Sai & Non- Leadership & B or Higher & Yes \\
\hline Zed & Non- Leadership & B or Higher & Yes \\
\hline
\end{tabular}

\section{Data Collection}

Data were downloaded from the Ethics and Leadership course's discussion board hosted on the university's learning management system. For the study, we examined students' initial posts for class Weeks 4, 8, and 13 (i.e., the beginning, middle, and end of term). We opted to study the initial posts only for several reasons: (a) they represented the most robust (i.e., content and length) response to the week's discussion questions (see Appendix A for questions), (b) they often represented students' most original thoughts because they asked about personal experiences and connection to readings, and (c) compared to more curt follow posts and 
comments, they offered more insight into students' deep learning about course concepts. In total, 105 initial posts ranging from 250 to 500 words each were examined.

\section{Data Coding and Coder Reliability}

As a research team of two- one instructional designer and one leadership studies faculty member (also instructor for the study's class) — we each coded the same 105 posts in accordance with our expertise using established a priori codes grounded in the relevant conceptual frameworks (see Tables 2 and 3). Given that we operated as single coders, in alignment with Koo and Li's (2016) and Belur's (2021) guidance, we assessed intra-coder reliability using the testretest approach - i.e., examining Pearson $r$ for each coder on identical discussion board passages coded 10 or more days apart. Results yielded acceptable reliability for cognitive skill coding $(r=.91, p<.05, \mathrm{~N}=35)$ as well as ethical leadership understanding $(r=.94, p<.05, \mathrm{~N}=35)$.

For specific codes applied to the student passages, Table 2 provides coding details for progressive cognitive skills based on Yang et al.'s (2011) model. Table 3 shares coding details relevant to understanding ethical leadership concepts. While Yang et al.'s model includes five factors for assessing cognitive skill (sharing and describing information (SDS), explaining, comparing, interpreting, clarifying (ECIC), analyzing, and concluding (AC), applying (A), and creating (C)), we omitted "analyzing and concluding" (AC) and "creating" (C) from our study. Based on our use of the coding framework for a previous study, intercoder reliabilities indicated that $\mathrm{AC}$ was challenging to pinpoint accurately, and $\mathrm{C}$ was not applicable to the online course discussion for the leadership coursework under consideration. To streamline data analysis, the coding procedure involved identifying the highest level of cognitive skill and ethical leadership understanding per post. This code was used in analysis. For example, if a passage showed both SDS and ECIC, ECIC was chosen as code because our study's aim was to parse out higher order cognitive skills and leadership meaning making.

\section{Table 2}

\section{General Cognitive Skill Indicators: From Simpler to Holistic Understanding}

Code Description from Guiding Conceptual Framework

\section{SDS-}

Sharing,

Seeking

Information

ECIC-

Explaining,

Comparing,

Interpreting,

Clarifying

A-Applying
"At this level, the discussions or postings are more opinions-oriented and without underlying reasoning, rationale, or explanations" (Yang et al., 2011, p. 10).

"At this level, the discussions or postings are ideas, suggestions, perspectives with underlying reasoning, rationale or personal explanations and examples" (Yang et al., 2011, p. 10).

"At this level, the application reflects the use or employment of a learned concept, principle, or tool, etc. in a similar way or situation as previously illustrated" (Yang et al., 2011, p. 11). 
Table 3

Ethical Leadership Meaning-Making Indicators: From Simpler to Holistic Understanding

\begin{tabular}{ll}
\hline Code & Description from Guiding Conceptual Framework \\
\hline Knowing & $\begin{array}{l}\text { Knowing and understanding. Knowledge of the development of values; } \\
\text { influence of systems on justice; models of valuing self and others; ethical } \\
\text { decision making (Komives et al., 2013). }\end{array}$ \\
Being & $\begin{array}{l}\text { Attitudes/opinions. Commitment to socially responsible behavior; authentic; } \\
\text { establishes sense of personal character; values integrity; expects high } \\
\text { standards (Komives et al., 2013). } \\
\text { Doing }\end{array}$ \\
& $\begin{array}{l}\text { Skills. Being congruent; being trusting; being reliable; having courage } \\
\text { (Komives et al., 2013). }\end{array}$ \\
\end{tabular}

\section{Data Analysis}

To address research questions one and two (i.e., If and to what extent do students express cognitive skills (or ethical leadership understanding) via weekly discussion boards over the course of the term?), each initial discussion post for Weeks 4, 8, and 13 was coded, per Table 2 and Table 3. To address the third research question (What, if any, is the relationship between expression of cognitive skill and ethical leadership understanding?), in addition to frequencies, z-tests were employed to test for significant differences between means of cognitive skill and ethical leadership representations for Weeks 4,8 , and 13. Z-tests were chosen instead of t-tests given that sample size surpassed 30. To address the fourth research question (What, if any, is the relationship between cognitive skill, ethical leadership understanding, and select student demographics (academic program, GPA, and prior leadership coursework), chi-square tests were conducted given the categorical nature of the variables. Academic program, GPA, and prior leadership coursework were dichotomous. Cognitive skill was transformed into a categorical variable by combining sharing and comparing into one variable. Similarly, for leadership understanding, knowing and being were combined. The rationale for this choice was based on the researchers' specific interest in isolating "application" and "doing" variables.

\section{Results}

\section{Expression of Students' Higher Order Cognitive Skills over Term}

The results for the first research question revealed that students were able to achieve the higher order cognitive skills (i.e., application) in Week 4. Students' posts reflected and integrated the use of a learned concept, theory, or principle in practice (Yang et al., 2011). The following excerpt from participant Carl's initial Week 4 discussion board post addressing the question of Can you recall a time where you were in a position of leadership and had to make a decision while remaining objective? Do you believe it is possible to always put aside our own personal bias? offers a helpful illustration of expressions of application-based cognitive skill:

While working as a supervisor for SeaWorld, I was leading a team that handled around $20 \mathrm{k}$ cash every day. There was a person on my team that was having money issues in his personal life. He was friends with me... He was a hard worker, and always there to help when I needed him to work more if needed. One day though investigations came to me with a report on this guy. He was stealing money when he can, and investigations had the 
stolen figure around 4-5k. They told me as supervisor I must present the report to him, and escort him to my director for termination. It was such a hard thing to do as I knew him and became friends with him, it was such a horrible 15-minute walk as he was pleading with me to defend him, and he would never do it again. Though I didn't want to turn him in, he did break many rules within our company, but also my ethics on stealing and being dishonest. I believe being a leader you must out aside your own bias as sometimes it can make you make the wrong choice.

However, Weeks 8 and 13 showed that most students' posts reflected sharing and comparing/explaining skills; higher order application decreased from $62.9 \%$ in Week 4 to $17.1 \%$ in Week 13 (see Table 4). Following is a discussion board excerpt from participant Connie, via which they share basic knowledge about ethical foundations in reply to In your own words, explain why it is important to lead ethically in your personal life in order to lead ethically in a professional context. Connie offers that "By having the foundation of an ethical individual, you will even be better equipped to take on the responsibility of leading others in an ethical manner, not just working alongside them."

Taking their thinking one step further but not quite to application, Christie digs a little more deeply and explains the place of crucibles in ethical leadership. She responds to Do you think it is possible to become a better leader after a crucible in one's life? as such:

Yes, it is possible to become a better leader after a crucible, because a crucible is a life experience that can change how you see or interact with the world. I have personally experienced good and bad moments that have shaped who I am now as a leader, and I know that this will continue to change based on my future experiences. I believe that the idea of "better" comes from the opportunity to reflect on and learn from your mistakes. I don't think that this ability is only due to age, but life chances and experiences.

Table 4

\begin{tabular}{llll}
\hline $\begin{array}{l}\text { Highest-Order } \\
\begin{array}{l}\text { Cognitive Skill } \\
\text { Expression Per }\end{array}\end{array}$ & Sharing & Comparing/Explaining & Application \\
$\begin{array}{l}\text { Post by Discussion } \\
\text { Week (N=35) }\end{array}$ & & & \\
Week 4 & $14.3 \%$ & $22.8 \%$ & \\
Week 8 & $17.1 \%$ & $57.2 \%$ & $62.9 \%$ \\
Week 13 & $42.8 \%$ & $40.1 \%$ & $25.7 \%$ \\
\hline
\end{tabular}

\section{Expression of Students' Ethical Leadership Understanding Over Term}

The results for the second research question revealed that only $20 \%$ of students demonstrated "doing" skills in Week 8, while no students expressed "doing" in Week 4. "Doing," with regard to a holistic understanding of ethical leadership, includes illustrations of being congruent, trusting, and reliable, and having courage (Komives et al., 2013). The following excerpt from participant Susan's Week 8 post on how they act out the ethical principles of moral courage in their lives offers a view of complex, holistic understanding and doing:

I definitely feel that I have moral courage...Now that I am a special education teacher, I certainly display moral courage more than ever. I have to stand up for my students and advocate for them when they cannot, and I always do what I feel is right whether or not there will be adverse consequences for me (i.e., socially within the school where I work, 
etc.). My love for my students and the population of individuals with exceptionalities in general has really brought out moral courage in me more than ever before.

Interestingly, in parallel with the decreases by Week 13 in application-based cognitive skills (see Table 4), students' expressions of “doing” also decreased by Week 13 (see Table 5). Overall, most students' posts reflected knowing and being, where "knowing" spoke to knowledge of ethical leadership models and associated systems and "being" represented attitudes. In their Week 4 discussion post, participant Susan expressed "knowing" as follows:

Utilitarianism is basically that the most "ethical" or "best" actions a person makes are the ones that are made with the consequences of those actions in mind, and actions that should be taken are the ones that have consequences that do the most "good."

Dell, also in Week 4, offered the following with regard to "being" and clearly illustrated their personal commitments, values, and self-understanding:

Altruism is about being invested in the wellbeing of others without any personal or social motives. It is an unselfish act of caring and compassion. It is important to practice altruism because someone's kind actions can cause others to practice altruism. We should be the change that we want to see in the world.

\section{Table 5}

Most Complex Ethical Leadership Understanding Per Post by Discussion Week (N=35)

\begin{tabular}{llll}
\hline & Knowing & Being & Doing \\
\cline { 2 - 4 } Week 4 & $0 \%$ & $100 \%$ & $0 \%$ \\
Week 8 & $0 \%$ & $80 \%$ & $20 \%$ \\
Week 13 & $0 \%$ & $91.4 \%$ & $8.6 \%$ \\
\hline
\end{tabular}

Relationship Between Expression of Cognitive Skill and Ethical Leadership Understanding

For the third research question, z-tests for means were conducted comparing the mean for cognitive skill scores to ethical leadership understanding scores for Weeks 4 , 8, and 13. For Week 4, we found that the cognitive skill mean $(M=2.52)$ was significantly different (at $p<.05)$ than the ethical leadership understanding mean $(\mathrm{M}=2)(\mathrm{z}=3.98, p=.000067)$. This result parallels frequencies for Week 4 indicating that posts did not express holistic meaning making - given the absence of ethical leadership "doing"; yet, with respect to cognitive skill, a combined $37.1 \%$ expressed simpler sharing/comparing and 62.9\% expressed higher order application (see Tables 4 and 5). For Week 8, we found that the cognitive skill mean $(M=2.06)$ was not significantly different (at $p<.05)$ than the ethical leadership understanding mean $(\mathrm{M}=2.21)(\mathrm{z}=-1.02$, $p=.305835)$. For Week 13, results indicated that the cognitive skill mean $(\mathrm{M}=1.76)$ was significantly different (at $p<.05)$ than the ethical leadership understanding mean $(\mathrm{M}=2.21)(\mathrm{z}=-$ $2.498, p=.013249$ ). Compared to expressions of ethical leadership understanding, which skewed toward "higher scoring" notions of being and doing, many students still expressed simpler cognitive skills related to sharing and describing.

\section{Relationship Between Cognitive Skill, Ethical Leadership Understanding, Student Profile}

For the final research question, we attempted chi-square tests given the categorical nature of the variables; two-by-two cross-tabulation tables were created for relationships between cognitive skill and each profile variable as well as ethical leadership understanding and each profile variable. Given our small sample size and, as a byproduct, tabulation table cell counts of less than five, the chi-square statistic was unviable - it uses an approximation because it assumes 
a large sample size (see Kim, 2017). As such, we calculated the Fisher Exact Test for each variable pairing because it does not approximate but uses an exact test for independence, thus, supporting the smaller sample. No significant associations emerged from the Fisher Exact Test.

For this final research question, we also calculated descriptive statistics by student variable across all weeks cumulatively to unpack themes in cognitive skill and leadership understanding expression. Overall, per Table 6, results indicated that, regardless of leadershipcentered major, GPA, or prior leadership coursework experience, students largely expressed sharing and comparing with regard to cognitive skill and knowing and being with regard to ethical leadership understanding. Interestingly, non-leadership major students, students with Below B GPAs, and students with no leadership coursework experience were more prone to expressions of doing. From a GPA perspective, specifically, students with Below B GPAs expressed application and doing more than their peers with GPAs of B or Higher.

Table 6

Students' Profiles in Relation to Cognitive Skills and Ethical Leadership Understanding (N=35) Ethical Leadership Understanding

\begin{tabular}{|c|c|c|c|c|}
\hline & $\begin{array}{l}\text { Knowing/ } \\
\text { Being }\end{array}$ & Doing & $\begin{array}{l}\text { Sharing/ } \\
\text { Comparing }\end{array}$ & Application \\
\hline Leadership Major $(\mathrm{n}=5)$ & $93 \%$ & $7 \%$ & $60 \%$ & $40 \%$ \\
\hline Non-Leadership Major $(n=30)$ & $90 \%$ & $10 \%$ & $65.6 \%$ & $34.4 \%$ \\
\hline$B$ and Higher GPA $(n=29)$ & $92 \%$ & $8 \%$ & $65.5 \%$ & $34.5 \%$ \\
\hline Below B GPA $(n=6)$ & $83 \%$ & $17 \%$ & $61.1 \%$ & $38.9 \%$ \\
\hline Prior Leadership Class $(n=25)$ & $92 \%$ & $8 \%$ & $65 \%$ & $35 \%$ \\
\hline No Prior Leadership Class $(n=10)$ & $87 \%$ & $13 \%$ & $63 \%$ & $37 \%$ \\
\hline
\end{tabular}

\section{Discussion and Implications}

This study provided a holistic exploration of how fostering knowledge construction in collaborative, student-led, asynchronous online discussions can inform and transfer to cognitive processes in leadership and other disciplines. Understanding three components (student-led discussions, leadership learning, and cognitive skills) can help create real world experiences aimed at bolstering meaningful application of leadership education. Specifically, this study offered new perspectives for understanding how student-led discussions can help undergraduate students make deeper meaning of leadership learning.

We found that connecting students to leadership theory and promoting "authenticity and meaningful exchange" (Smith, 2015, p. 232) in student-led discussions is a valuable instructional technique. For example, students' weekly online, asynchronous discussion posts over the course of the semester for Ethics and Leadership showed that, of all the expressions of ethical leadership understanding, "being" was most robust across all weeks with "doing" peaking in Week 8 (i.e., $20 \%$ ) and declining to $8.6 \%$ in Week 13. Next, expressions of the highest order cognitive skill (i.e., application) were most abundant in Week 4 (the first week of discussion). Expressions of application declined by the final discussion in Week 13 and, in fact, by Week 13, "sharing" represented the most prevalent cognitive skill expression. The frequencies of both "being" and "sharing" in students' posts suggest that students were actively involved in negotiations of their own ideas in a collaborative, meaningful dialogue (Baran \& Correia, 2009). At the same time, results may indicate that students were uncertain about how to convey lived experiences; they 
needed more guidance in translating being-based attitudes to action. Results also suggest that, perhaps, students were too burdened by end-of-term fatigue or time pressures to engage fully in discussion. In their research, Galbraith and Merrill (2012) found that student exhaustion and cynicism did indeed increase over the academic cycle. This finding, combined with current day concerns such as Zoom fatigue (see Fauville et al., 2021), offers context for decreased end-ofterm engagement with online collaborations and discussions.

Regarding question framing and support with expressions of lived experience, Akin and Neal (2007) affirmed the importance of online discussion questions that honored experiential learning and that were "designed around a concept or theory being taught but aimed directly at the personal story of the student" (p. 195). Though students creating weekly discussion questions for classmate engagement were given instructor support in crafting higher order questions based on the revised Bloom's Taxonomy of learning, this study's findings suggest that question development guidance could have been more explicit: Though discussions are "student-led," students may need more scaffolding. Our findings support previous studies that also suggest questioning technique for peer facilitation (Chen et al., 2019; Hosler \& Arend, 2013). For example, facilitation questions can ask for explanation of how and why, or for evidence drawn from life experience. Further, given that meaning making is both a cognitive and emotional process (Komives et al., 2013), perhaps, our findings suggest that students could benefit with deeper work in the course linking the conceptual to sense of value, purpose, and their own commitments. To this end, individual journals and reflective assignments could be essential processing partners to more collaborative, online discussion-based assignments.

Additionally, students' decreased motivation could be tied to students' strategies and regulatory skills in online discussions. Park and Yun (2017) found that undergraduate students used performance-avoidance strategies to avoid peers making fun of their poor performance. Whether reasons for dips in participation and engagement are attributed to exhaustion or selfconsciousness, instructors, particularly leadership educators, can play a vital role in connecting students with course content and with each other by centering notions of mattering and belonging, and by employing andragogical principles (see Knowles, 1973) such as helping students understand why a topic is important to learn. Additionally, educators can help sustain motivation by exploring their classrooms as "communities of practice" (Lave, 1991) that exist not solely for knowledge transactions but also for helping students develop identities as leadership practitioners fully encompassing learning as a social process.

This question of how best to scaffold, support, and sustain students as learners and practitioners is not only necessary to interrogating and revising pedagogy, but it is also of import to future research. Prospective studies might consider examining the arc of student motivation throughout their asynchronous, online discussion board engagement as a way of unpacking student needs and identifying strategies instructors can employ to craft a connected learning community. This research could be particularly helpful in the context of exploring how to support less-engaged students as they cross comfort zones in discussion facilitation and connection creation. Afterall, "connection" is essential to leadership learning.

In tandem with our exploration of the presence and extent of cognitive skill and ethical leadership understanding over the course of the term, our study also examined the relationship between these expressions. Our conceptual frameworks (i.e., Yang et al.'s (2011) model for assessing cognitive learning in online discussions and the Relational Leadership Model (Komives et al., 2013)) offer perspectives on holistic thinking that invite a continuum from foundational to more complex and higher order understanding. As such, we sought to unpack if 
there were parallels between the models across Weeks 4, 8, and 13. We found that means differed between sets of expressions for Weeks 4 and 13, indicating that cognitive skills of sharing/comparing and applying did not map to ethical leadership understanding of knowing/being and doing. This finding not only suggests that descriptions for sharing/comparing are inconsistent with those for knowing and being, but also that "applying" from a cognitive skill perspective is more general than what "doing" encompasses in the Relational Leadership Model.

While "applying" in Yang et al.'s work encompasses hypotheticals, "doing” speaks to explicit actions, follow through, and commitments. Thus, at face value, student posts are far more likely to fall into the applications category than the "doing" category. Given this observation, while Lee and Martin (2017) found that students preferred application questions to analysis, synthesis, judgement, comprehension, or facts, we must interrogate what we mean by "application." Are we asking students to extrapolate, hypothesize, or offer what could be in their lives or lives of others? Are we asking students to speak to specific ways in which they enact course principles (e.g., ethical leadership) every day? If the latter, are we prepared to scaffold students' thinking and provide spaces in our online courses that encourage enactment and mistake-making? As educators, we must engage in deep discourse around these questions.

Finally, while we did not discover any significant associations between student profile variables, cognitive skill, and ethical leadership understanding, we did discover that, regardless of major, GPA, or prior leadership coursework experience, students largely expressed sharing and comparing with regard to cognitive skill and knowing and being with regard to ethical leadership understanding. From a GPA perspective, specifically, students with Below B GPAs expressed application and doing more than their peers with GPAs of B or Higher. Given that GPA is often used as an indicator to predict students' success in online courses (Boston et al., 2012), our findings suggest that GPA alone cannot be used to contextualize student outcomes. This finding supports the notion that our view of students must be holistic in nature. While holism and relational processes are integral to leadership education (Guthrie et al., 2017; Komives et al., 2013) online or face-to-face, we must extend the importance of holism to online learning, writ large, as a guide toward teaching practice that meets students where they are, dismantles assumptions about their success and capacity, and centers collaborative, online discussions as spaces for efficacy-building.

\section{Limitations}

While this study offers potential new insight, five major limitations must be acknowledged. First, this study was based on secondary data, which though rich, bounded our analysis and limited complex examinations of student demographics, exploration of granularity in familiarity with leadership concepts, and unpacking of experiences in relation to expressed cognitive skills and ethical leadership understanding. Second, our data set was modest in size $(\mathrm{N}=35)$, which also limited the nature of our analytics (e.g., use of regression) given potential convergence issues. Third, our study focused on only the "ethical" component of the Relational Leadership Model, but the model encompasses a larger framework that, from a systems perspective, would impact assessments of student learning. Fourth, the types of discussion questions to which students responded changed weekly, thus, there was no control the way students were invited to demonstrate understanding. Lastly, our study only examined students' initial discussion posts for each week and did not unpack subsequent posts and classmate comments, which could have added more texture to the overall analysis. 


\section{Conclusion}

The purpose of this study was to examine 35 students' collaborative discussion board posts at the beginning, middle, and end of an online, asynchronous Ethics and Leadership class to assess not only if and to what extent students express cognitive skills, in general, but also if and to what extent they understand ethical leadership via these discussions. Additionally, we also examined if there was a relationship between expression of higher order cognitive skills and more complex ethical leadership understanding. Our findings, though exploratory, offered insight into the intersections between online discussion boards, leadership learning, and cognitive skill as well as implications for engaging students in collaborative learning via asynchronous online discussions. In a world focused on a digital future (Munshi et al., 2019) and demanding individuals versed in intentional leadership practice (O'Keefe \& Meeker, 2019), our study offers potential insight into how digital pedagogy aimed at collaborative practices can foster undergraduates' purposeful, inclusive, empowering, ethical, and process-oriented leadership practice (Komives et al., 2013). This work not only provides researchers a springboard for further exploration into the nexus between digital learning, student development, and learning outcomes, but also offers a space for a continued discourse, especially among leadership educators, about pedagogies and practices that transcend time and place for learning.

\section{Declarations}

The author(s) declared no potential conflicts of interest with respect to the research, authorship, and/or publication of this article.

The author(s) received approval from the ethics review board of George Mason University for this study.

The author(s) received no financial support for the research, authorship, and/or publication of this article. 


\section{References}

Akin, L., \& Neal, D. (2007). CREST+ model: Writing effective online discussion questions. Journal of Online Learning and Teaching, 3(2), 191-202.

https://doi.org/10.1891/9780826134097.0007

Aloni, M., \& Harrington, C. (2018). Research based practices for improving the effectiveness of asynchronous online discussion boards. Scholarship of Teaching and Learning in Psychology, 4(4), 271-289. https://doi.org/10.1037/st10000121

Anderson, L. W., Krathwohl, D. R., \& Associates. (2001). A taxonomy for learning, teaching, and assessing: A revision of Bloom's taxonomy of educational objectives. Longman.

Baran, E., \& Correia, A-P. (2009). Student-led facilitation strategies in online discussions. Distance Education, 30(3), 339-361. https://doi.org/10.1080/01587910903236510

Belur, J., Tompson, L., Thornton, A., \& Simon, M. (2021). Interrater reliability in systematic review methodology: Exploring variation in coder decision-making. Sociological Methods \& Research, 50(2), 837-865. https://doi.org/10.1177/0049124118799372

Bloom, B. S. (1956). Taxonomy of educational objectives: The classification of educational goals. Longman.

Bleich, M. R. (2020). The discussion board in online learning: Leadership development opportunities. The Journal of Continuing Education in Nursing, 51(12), 541-543. https://doi.org/10.3928/00220124-20201113-03

Boston, W., Ice, P., \& Burgess, M. (2012). Assessing student retention in online learning environments: A longitudinal study. Online Journal of Distance Learning Administration, 15(2).

Chen, Y., Lei, J., \& Cheng, J. (2019). What if online students take on the responsibility: Students' cognitive presence and peer facilitation techniques. Online Learning, 23(1), 37-61. https://doi.org/10.24059/olj.v23i1.1348

de Brey, C., Snyder, T. D., Zhang, A., \& Dillow, S. A. (2021). Digest of Education Statistics 2019 (NCES 2021-009). National Center for Education Statistics, Institute of Education Sciences, U.S. Department of Education. Washington, DC.

https://nces.ed.gov/pubs2021/2021009.pdf

Dennen, V. P., \& Wieland, K. (2007). From interaction to intersubjectivity: Facilitating online group discourse processes. Distance Education, 28(3), 281-297.

https://doi.org/10.1080/01587910701611328

deNoyelles, A., Zydney, J. M., \& Chen, B. (2014). Strategies for creating a community of inquiry through online asynchronous discussions. Journal of Online Learning and Teaching, $10(1), 153-165$. 
de Oliveira, L. \& Olesova, L. (2013). Learning about the literacy development of English language learners in asynchronous online discussions. Journal of Education, 193(2), 15-23. https://doi.org/10.1177/002205741319300203

De Wever, B., Van Keer, H., Schellens, T., \& Valcke, M. (2010). Roles as a structuring tool in online discussion groups: The differential impact of different roles on social knowledge construction. Computers in Human Behavior, 26(4), 516-523.

https://doi.org/10.1016/j.chb.2009.08.008

Dewey, J. (1938). Experience and education. Macmillan

Dugan, J. P. (2017). Leadership theory: Cultivating critical perspectives. John Wiley \& Sons.

Dugan, J. P., \& Humbles, A. D. (2018). A paradigm shift in leadership education: Integrating critical perspectives into leadership development. New Directions for Student Leadership, 2018(159), 9-26. https://doi.org/10.1002/yd.20294

Fauville, G., Luo, M., Muller Queiroz, A. C., Bailenson, J. N., \& Hancock, J. (2021). Zoom Exhaustion \& Fatigue Scale. SSRN Electronic Journal. https://doi.org/10.2139/ssrn.3786329

Friedman, J. (2018). Study: More students are enrolling in online courses. US News and World Report. https://www.usnews.com/higher-education/online-education/slideshows/discover-10current-trends-in-online-education

Galbraith, C. S., \& Merrill, G. B. (2012). Academic and work-related burnout: A longitudinal study of working undergraduate university business students. Journal of College Student Development, 53(3), 453-463. https://doi.org/10.1353/csd.2012.0044

Garrison, D. R., Anderson, T., \& Archer, W. (2001) Critical thinking, cognitive presence, and computer conferencing in distance education, American Journal of Distance Education, 15(1), 7 23. https://doi.org/10.1080/0892364010952707 1

Gee, J. P. (2015). Discourse, small d, big D. In K. Tracy, T. Sandel and C. Ilie (Eds.), The International Encyclopedia of Language and Social Interaction, 3, 1-5. https://doi.org/10.1002\%2F9781118611463.wbielsi016

Gunawardena, C. N., Lowe, C. A., \& Anderson, T. (1997). Analysis of a global online debate and the development of an interaction analysis model for examining social construction of knowledge in computer conferencing. Journal of Educational Computing Research, 17(4), 397431.

Guthrie, K. L., Jones, T. B., \& Osteen, L. (Eds.). (2016). Developing culturally relevant leadership learning: New directions for student leadership, (No. 152). John Wiley \& Sons. 
Guthrie, K. L., \& Meriwether, J. L. (2018). Leadership development in digital spaces through mentoring, coaching, and advising. New Directions for Student Leadership, 2018, 99-110. https://doi.org/10.1002/yd.20291

Harasim, L. (2000). Shift happens: Online education as a new paradigm in learning. The Internet and Higher Education, 3(1-2), 41-61. https://doi.org/10.1016/s1096-7516(00)00032-4

Heaton, J. (2008). Secondary analysis of qualitative data: An overview. Historical Social Research/Historische Sozialforschung, 33-45.

Hew, K. F. (2015). Student perceptions of peer versus instructor facilitation of asynchronous online discussions: Further findings from three cases. Instructional Science, 43(1), 19-38. https://doi.org/10.1007/s11251-014-9329-2

Hew, K. F., \& Cheung, W. S. (2011). Higher-level knowledge construction in asynchronous online discussions: an analysis of group size, duration of online discussion, and student facilitation techniques. Instructional Science, 39(3), 303-319. https://doi.org/10.1007/s11251$\underline{010-9129-2}$

Higher Education Research Institute. (1996). A social change model of leadership development. Higher Education Research Institute.

https://www.heri.ucla.edu/PDFs/pubs/ASocialChangeModelofLeadershipDevelopment.pdf

Hrastinski, S. (2018). A study of asynchronous and synchronous e-learning methods discovered that each supports different purposes. EDUCAUSE Quarterly, 31(4). http://wwwcdn.educause.edu/library/EQM0848

Hsieh, H. F., \& Shannon, S. E. (2005). Three approaches to qualitative content analysis. Qualitative Health Research, 15(9), 1277-1288. https://doi.org/10.1177/1049732305276687

Hsu, T., Wang, H. F., \& Hong, M. C. (2003). Effects of gender, GPA, computer self-efficacy, and learning motivation on the collaborative e-learning participation. In A. Rossett (Ed.), Proceedings of E-Learn 2003--World Conference on E-Learning in Corporate, Government, Healthcare, and Higher Education (pp. 241-248). Association for the Advancement of Computing in Education (AACE).

Jeanneau, C., \& O'Riordan, S. (2020). The impact of a peer-facilitated discussion initiative on international students' learning experience in the context of internalization at home. Language Learning in Higher Education, 10(1), 1-24. https://doi.org/10.1515/cercles-2020-2011

Jenkins, D. (2016). Teaching leadership online: An exploratory study of instructional and assessment strategy use. Journal of Leadership Education, 15(12), 129-149.

https://doi.org/10.12806/V17/I1/R2

Johansson, E. (2020). The assessment of higher-order thinking skills in online EFL courses: A quantitative content analysis. English Studies, 19(1), 224-256. https://doi.org/10.35360/njes.519 
Kennedy, D. (2004). The role of a facilitator in a community of philosophical inquiry. Metaphilosophy, 35(5), 744-765. https://doi.org/10.1111/j.1467-9973.2004.00348.x

Kennedy, N. S., \& Kennedy, D. (2010). Between chaos and entropy: community of inquiry from a systems perspective. Complicity: An International Journal of Complexity and Education, 7(2). https://doi.org/10.29173/cmplct8917

Kim H. Y. (2017). Statistical notes for clinical researchers: Chi-squared test and Fisher's exact test. Restorative Dentistry \& Endodontics, 42(2), 152-155.

https://doi.org/10.5395/rde.2017.42.2.152

Knowles, M. (1973). The adult learner: A neglected species. Gulf.

Komives, S. R., Lucas, N., \& McMahon, T. R. (2013). Exploring leadership: For college students who want to make a difference (3rd ed.). Jossey-Bass.

Komives, S. R., Wagner, W., \& Associates. (2016). Leadership for a better world: Understanding the social change model of leadership development. Wiley.

Koo, T. K., \& Li, M. Y. (2016). A guideline of selecting and reporting intraclass correlation coefficients for reliability research. Journal of Chiropractic Medicine, 15(2), 155-163. https://doi.org/10.1016/j.jcm.2016.02.012

Laal, M., \& Ghodsi, S. M. (2012). Benefits of collaborative learning. Procedia-Social and Behavioral Sciences, 31, 486-490. https://doi.org/10.1016/j.sbspro.2011.12.091

Lave, J. (1991). Situating learning in communities of practice. In L. B. Resnick, J. M. Levine, \& S. D. Teasley (Eds.), Perspectives on socially shared cognition (pp. 63-82). American Psychological Association. https://doi.org/10.1037/10096-003

Lee, J., \& Martin, L. (2017). Investigating students' perceptions of motivating factors in online class discussions. International Review of Research in Open and Distributed Learning, 18(5), 148-172. https://doi.org/10.19173/irrodl.v18i5.2883

Lim, F. P. (2017). An analysis of synchronous and asynchronous communication tools. Advanced Science and Technology Letters, 143(AST 2017), 230-234.

https://doi.org/10.14257/ast1.2017.143.46

McCarron, G. P., Jackson, G. R., McNaughtan, J. L., Olesova, L., Schmidt, G. B., \& Adams, T. T. (2020). Centering dialogic and digital approaches in leadership education pedagogy: Priority 6 of the National Leadership Education Research Agenda 2020-2025. Journal of Leadership Studies, 14(3), 72-77. https://doi.org/10.1002/jls.21716

McRay, J., Goertzen, B., \& Klaus, K. (2016). Student-moderated discussion boards in a graduate online course. Journal of Leadership Education, 15(1), 150-160.

https://doi.org/10.12806/v15/i1/a6 
Moallem, M. (2015). The impact of synchronous and asynchronous communication tools on learner self-regulation, social presence, immediacy, intimacy, and satisfaction in collaborative online learning. The Online Journal of Distance Education and e-Learning, 3(3), 55-77.

Munshi, M., Kuril, S., Sharif Khan, D., Shrimali, T., \& Gaur, S. (2019). Strategic evolution from confinement of face to face learning and shift to online learning. International Educational Applied Research Journal, 3(10), 32-38.

O'Keefe, S., \& Meeker, C. (2019). Career readiness through leadership education [Audio Podcast]. National Association of Student Personnel Administrators (NASPA). Retrieved from https://soundcloud.com/user-606900324-709612745/episode-58-career-readiness- throughleadership-education

Owen, J. E. (Ed.). (2015). Innovative learning for leadership development. New Directions for Student Leadership, (No. 145). Wiley.

Perrotta, K. (2020). Getting HIP: A study on the implementation of asynchronous discussion boards as a high-impact practice in online undergraduate survey history courses. The Journal of Social Studies Research, 44(2), 209-217. https://doi.org/10.1016/j.jssr.2020.02.001

Peterson, A. T., Beymer, P. N., \& Putnam, R.T. (2018). Synchronous and asynchronous discussions: Effects on cooperation, belonging, and affect. Online Learning, 22(4), 7-25. https://doi.org/10.24059/olj.v22i4.1517

Purcell, J. W. (2017). Community-engaged pedagogy in the virtual classroom: Integrating eService-learning into online leadership education. Journal of Leadership Studies, 11(1), 65-70. https://doi.org/10.1002/jls.21515

Rose, S., Spinks, N., \& Canhoto, A. I. (2015). Management research: Applying the principles. Routledge.

Roseth, C. J., Saltarelli, A. J., \& Glass, C. R. (2011). Effects of face-to-face and computer mediated constructive controversy on social interdependence, motivation, and achievement. Journal of Educational Psychology, 103, 804-820. https://doi.org/10.1037/a0024213

Rost, J. C., \& Barker, R. A. (2000). Leadership education in colleges: Toward a 21st century paradigm. Journal of Leadership Studies, 7(1), 3-12.

https://doi.org/10.1177/107179190000700102

Rourke, L., Anderson, T., Garrison, D. R., \& Archer, W. (2001). Methodological issues in the content analysis of computer conference transcripts. International Journal of Artificial Intelligence in Education, 12, 8-22.

Schindler, L.A., \& Burkholder, G.J. (2014). Instructional design and facilitation approaches that promote critical thinking in asynchronous online discussions: A review of the literature. Higher Learning Research Communications, 4(4), 11-29. https://doi.org/10.18870/hlrc.v4i4.222 
Smith, D. N. (2015). Effectively using discussion boards to engage students in introductory leadership courses. International Journal of Leadership in Education, 14(2), 230-237. https://doi.org/10.12806/v14/i2/ab3

Ulum, Ö. G. (2016). A descriptive content analysis of the extent of Bloom's taxonomy in the reading comprehension questions of the course book Q: Skills for success 4 reading and writing. The Qualitative Report 21(9), 1674-1683. https://doi.org/10.46743/2160-3715/2016.2172

Waters, J. (2012). Thought-leaders in asynchronous online learning environments. Journal of Asynchronous Learning Networks, 16(1), 19-33. https://doi.org/10.24059/olj.v16i1.219

Williams, L., \& Lahman, M. (2011). Online discussion, student engagement, and critical thinking. Journal of Political Science Education,7(2),143-162.

https://doi.org/10.1080/15512169.2011.564919

Yang, D., Richardson, J. C., French, B. F., \& Lehman, J. D. (2011). The development of a content analysis model for assessing students' cognitive learning in asynchronous online discussion. Educational Technology Research and Development, 59(1), 43-70. https://doi.org/10.1007/s11423-010-9166-1

Xie, K. \& Ke, F. (2011). The role of students' motivation in peer-moderated asynchronous online discussions. British Journal of Educational Technology, 42(6), 916-930. https://doi.org/10.1111/j.1467-8535.2010.01140.x 


\section{Appendix A}

Student-Created Ethical Leadership in the News Discussion Questions by Week

\begin{tabular}{|c|c|}
\hline Week & Discussion Question Prompt \\
\hline
\end{tabular}

Week Q1: How can leaders of organizations clarify their mission and values, to make it clear

4 that they are an ethical organization, and ethics is not negotiable?

Exploration

Q2: In your own words, explain why it is important to lead ethically in your personal life to lead ethically in a professional context.

Exploration

Q3: Knowing that the religious beliefs of the supreme court judges influence their character and knowing that majority of our supreme court judges are making decisions based on their religious convictions, do you think their decisions will be truly ethical and Exploration for the good for the majority of the country?

Q4: Can you recall a time where you were in a position of leadership and had to decide while remaining objective? Do you believe it is possible to always put aside our own personal bias?

Week Q1: Do you have moral courage? If so, how did you learn to use moral courage? For

8 example, did you discuss it with someone and wanted to be better, did you look up to

Application

Exploration someone growing up or have a role model, and/or did you learn by just practicing it or by learning about it?

Q2. If you were a business leader running your own company, how would you use the Ethical Leaders Decision Tree? For what type of decisions? All ethical decisions? Some ethical decisions? Explain why.

Application

Q3. Out of the five different approaches of ethical standards that we should use, which one do you think is the best and most useful approach and why? Have you found yourself using one of these approaches in your life? If so, when?

Application

Q4: Given all three stories in the article, do you agree with the author's responses? If not, what would you have done in each story, and why do you disagree or agree?

Application

Week Q1: In the article from Fast Company, which leader do you resonate with most, and why, Exploration

13 and which leader's actions do you least agree with, and why?

Q2: Based on Maxwell's Chapter 7 and the Crucibles of Leadership reading, is it possible for organizations to simultaneously enact the Midas Touch and the four skills of leadership? If so, how can these organizations do so effectively?

Application

Q3: Do you think it is possible to become a better leader after a crucible in one's life?

Please explain your reasoning.

Q4: What is your definition of ethical leadership-based Maxwell's conclusion? What other course connections can you draw to support your answer?

Exploration 